\title{
Integrating Technology in the Classroom to Engage Students
}

\section{Dr. Chadia A. Aji, Tuskegee University}

Chadia Affane Aji is a Professor in the Department of Mathematics at Tuskegee University. Dr. Aji received her Ph.D. and M.S. in Mathematics from Auburn University and a Bachelor in Chemical Engineering from Texas A\&M University. Her research interests lie in the areas of numerical analysis, computational applied mathematics, complex analysis, and on improving students' learning in STEM disciplines. Dr. Aji is involved in retention activities at Tuskegee University. She helps designing strategies to assist incoming freshmen cope with the first year mathematics classes. She has also developed teaching modules to improve students' learning in mathematics using technology.

\section{Dr. M. Javed Khan, Tuskegee University}

Dr. M. Javed Khan is Professor and Head of Aerospace Science Engineering Department at Tuskegee University. He received his Ph.D. in Aerospace Engineering from Texas A\&M University, M.S. in Aeronautical Engineering from the US Air Force Institute of Technology, and B.E. in Aerospace Engineering from the PAF College of Aeronautical Engineering. He also has served as Professor and Head of Aerospace Engineering Department at the National University of Science and Technology,Pakistan. His research interests include experimental aerodynamics, aircraft design and engineering education. 


\title{
Engaging Middle School Students in STEM using a Flight Simulation Learning Environment
}

\author{
Chadia A. Aji and M. Javed Khan \\ Tuskegee University, Tuskegee AL 36088
}

\begin{abstract}
This paper will share the design of a learning environment that uses flight simulator-based activities designed to cognitively engage middle school students. The flight simulator provides an exciting, realistic, and engaging learning experience. It allows students to recognize the linkage between the concepts and application in real-world. Lesson plans were developed for several math and physics concepts integrating the flight simulator activities. To ensure buy-in for classroom implementation, the topics of these lessons were identified in consultation with the local middle school STEM teachers. Professional development on using the pedagogical approach was then provided to teachers from the middle schools that serve primarily underrepresented populations. Middle school students experienced the learning environment as part of a summer camp to deeply understand some science and math concepts. A quasi experimental between-subjects research design was used. Pre-post content and attitude instruments were utilized to collect data for determining the effectiveness of the approach. This paper provides an updated analysis $(\mathrm{N}=50)$ combining the previously reported data from the 2017 camp and the implementation results of the summer 2018 camp. Results indicated statistically significant gains in students' content knowledge and positive changes in attitudes of mainly female students towards science, technology, engineering and math.
\end{abstract}

\section{Keywords}

STEM, K-12, flight simulation, mathematics, science

\section{Introduction}

The U. S. K-12 education system is facing several challenges which are of grave concern especially in context of the U.S. technological leadership of the world. These challenges include the continued global non-competitive performance of U.S. middle school students in science and mathematics in comparison to other industrialized nations of the world. According to the Program for International Students Assessment (PISA) report of 2015, U.S. 15-year-olds placed $24^{\text {th }}$ in science while students from 17 countries scored significantly higher than the U.S. students [1]. In math, the U.S. students were placed $39^{\text {th }}$ which is which is significantly lower than the average performance of students from the 36-member countries of the Organization for Economic Cooperation and Development (OECD) who took part in the assessment as reported in the PISA 2015 [1]. A comparison of data from PISA scores of 2000-2015 did not indicate any significant change in the performance of U.S. students in science, while in math the score in 2015 was significantly lower $(\mathrm{p}<0.05)$ than previous years [2]. The national achievement gap in U.S. between racial and ethnic minorities, and White students is another area of concern. The PISA 2015 data indicated that the scores in science literacy of Black and Hispanic students were significantly lower $(\mathrm{p}<$ 
0.05) than White students [2]. There are several structural reasons such as low socio-economic status [3], and non-availability of qualified teachers for this below par performance and the achievement gap [4]-[7].

While there may be other reasons impacting performance e.g. financial, from a pedagogical perspective, the low performance of US students is due to the lack of interest in science, technology, engineering and math (STEM). One reason for this lack of interest is the unengaging learning environments as reported in the High School Survey of Student Engagement [8]. This survey which was administered to more than 42,000 high school students and covered 103 schools in 27 states, found that $66 \%$ of U.S. students were bored, citing uninteresting and irrelevant materials in the classroom. Bridgeland, Dilulio and Morrison [9] identified that the major cause $(46 \%)$ of school drop-out was the uninteresting nature of the classroom. Student engagement is therefore an important element of academic success, persistence and retention. Handelsman et al. [10] determined four dimensions of student engagement at the course level being skills, participation/interaction, emotional and achievement. Fredricks et al. [11] suggested the three important dimensions of students' engagement as behavioral, emotional, and cognitive. They noted that within each dimension, there could be a wide variation of intensity. They further broke these dimensions down into multiple categories. Involvement in learning is one of the categories of the behavioral domain, which they identified as consisting of persistence, effort, concentration, asking questions, and contributing to class discussion. They considered boredom, interest, and anxiety as aspects of the emotional dimension, while learning strategies such as rehearsal, summarizing and elaboration to retain, organize and understand the material as elements of the cognitive domain.

Engaging students who are not interested in STEM is a challenge. Strategies that are grounded in theories of engagement therefore need to be devised. Active learning is one such strategy. If properly designed, active learning environments promotes engagement in all the three dimensions (behavioral, cognitive and emotional) resulting in reducing absenteeism, boosting cooperative learning skills, and improving academic performance [12]. Students are motivated to learn when they perceive that "1) they are empowered, 2) the content is useful, 3) they can be successful, 4) they are interested, and 5) they feel cared about by the instructor and/or other students" [13]. Marzano, Pickering and Heflebowen [14] noted that a pedagogical environment that elicits positive responses to questions: "a) How do I feel? b) Am I interested? c) Is it important? and d) Can I do this?" may indicate an engaged student. Such an environment leads to self-efficacy which has been defined by Bandura [15] as "how well one can execute courses of action required to deal with prospective situations". Academic achievement and self-efficacy have been empirically shown to be related [16]-[20]. Successful learning enhances an individual's self-efficacy [21]-[23].

The objective of this work is to assess an innovative active learning environment. In view of the achievement gap between White students and African-American students, the target population of the research is underrepresented middle school students from a rural county with low socioeconomic status. The active learning environment was designed based on the three dimensions of engagement (behavioral, cognitive and emotional). The approach is to make the learning 'interesting' and 'relevant'. These characteristics were achieved through the use of a flight simulation software that allowed students to recognize the relevance of math and science to real life while conducting hands-on activities (collecting, analyzing and interpreting data). 


\section{Method}

The active learning environment was implemented using desktop flight simulation (Fig. 1) and a large screen flight simulator that had three out-of-window views (Fig. 2). The desktop set up included a joystick with an integrated throttle. The large screen out-of-window views were generated by three ultra-short-throw LCD projectors set up in a rear projection mode. The LCD projectors were driven by three dedicated PCs which were slaved to a fourth PC that served as the master. The Wideview [24] shareware was used to slave the out-of-the-window computers to the master computer through the FSUIPC [25] shareware. The master PC also powered the instrument panel display. A commercial-off-the-shelf flight simulator seat was used for the large screen flight simulator setup. The flight control yoke and throttle were connected to the master PC and attached to the seat. The Microsoft Flight Simulator X (FSX) software was used to provide hands-on activities (missions).

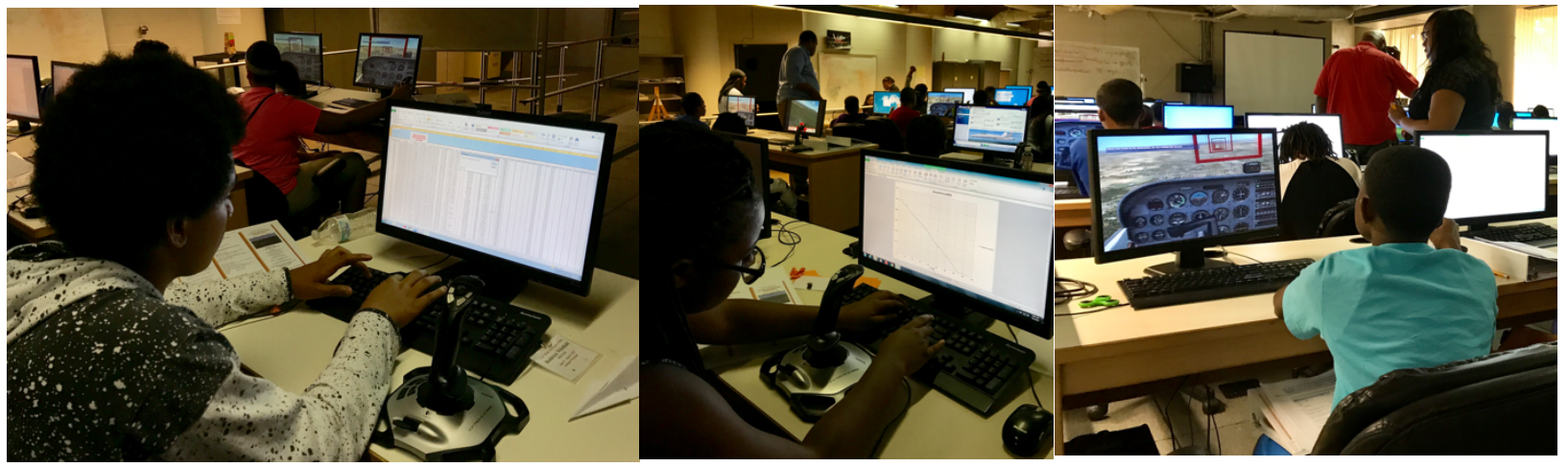

Figure 1: Students using desktop setup during summer

The FSX missions were appropriately designed to ensure that the students who were novices at flying could collect good data for analysis. For example, the flight lesson on "slope" was designed to ensure that the altitude and heading cannot be changed by the student. The only control available to the student was the throttle to accelerate or decelerate the aircraft.

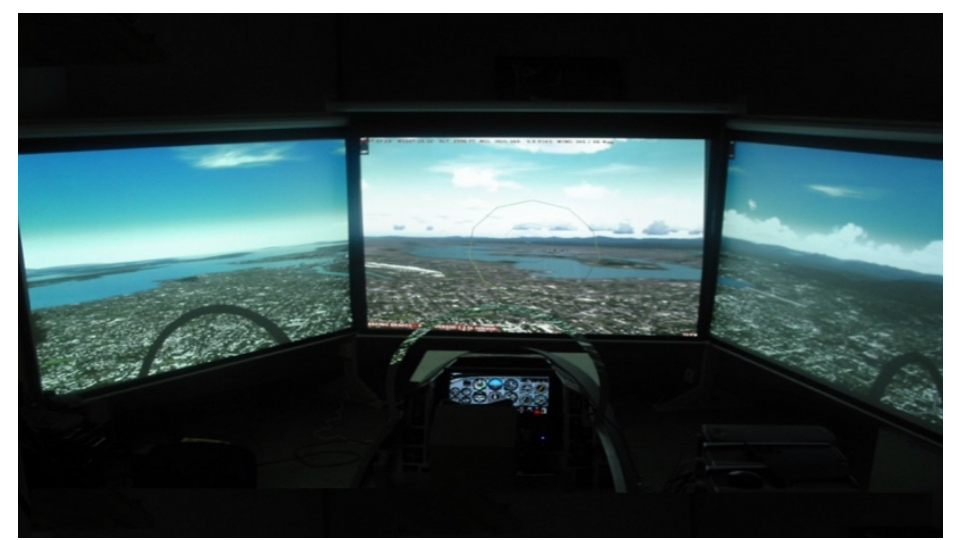

Figure 2: Large screen set up

Challenging math and science concepts were identified during meetings with the middle school teachers of the local school district. Several learning modules for concepts that were amenable to flight simulator hands-on activities have been developed. Some of these modules are slope/rate of change/acceleration-deceleration, ratio and proportion, conservation of energy (potential and kinetic), and momentum. The learning modules followed the 5E approach of Engage, Explore, Explain, Extend, Evaluate [26]. Each learning module consists of (a) Basics, (b) Paper and pencil activity, (c) Flight simulator activity, (d) Data analysis and interpretation. The learning modules 
were designed to be completed in two 75 minutes class periods. The learning materials are accessible on the project website http://flyhightu.weebly.com.

The intervention was a one-week long summer camp. The participants of the summer camp were 7 th and 8th grades students $(\mathrm{N}=50$, females $=25$, males $=25)$. All these students were from an economically depressed rural school district, and self-identified as African-American.

The summer camp consisted of several components including learning about (a) Physics of flight, (b) Aircraft controls and instruments, (c) Flying the flight simulator, (d) Physics and math content, (d) Excel, (d) Data collection, and (e) Data analysis and interpretation. The student participants first learned about the basics of the Physics of flight which was followed by an introduction to how an aircraft is controlled in flight. They then practiced flying the flight simulator. The students then learned a math/physics concept and did pencil and paper activities. These activities were followed by flying a mission and collecting data. Next, students used Excel to plot the data to compare their results with those from the paper-pencil exercises.

A quasi-experimental within-subject research design was used to determine the impact of the intervention on the participants' attitudes towards STEM and their content knowledge. The impact of the intervention on the participants attitudes towards STEM was assessed using a 65-item survey (5-Point Likert Scale) that was administered pre and post camp. A content assessment instrument (25-items each for math and science) was also administered to the participants pre-camp and post camp. The participants were given a post camp survey as well.

\section{Results and Discussion}

The Math and Science Attitudes pre-post responses were analyzed using paired two-tail t-test at a significance level of $p<0.05$. The 65 -items of the survey loaded on four dimensions (D1, D2, D3, D4) as defined in Table-I. While most of the responses indicated a positive change in attitudes towards STEM, only few questions which are included in Table 1 registered a statistically significant change. The pre-post analysis indicated that the intervention was more effective in influencing the attitudes of the female (F) participants than the male (M) participants. The selfefficacy of the female participants increased in math (D2) and science (D3). In the pretest, the female students had a statistically lower average response as compared to the male students about the effectiveness of the flight simulator in learning math and science (D5). However, a statistically significant positive change in attitude of female students towards the use of the flight simulator was observed post intervention. There was no post-camp change in the male students' attitude towards the use of the flight simulator. The only area in which the male students registered a significant change was their recognition of the importance of math (D1).

\begin{tabular}{|l|l|l|}
\hline $\begin{array}{l}\mathrm{M}=25 ; \mathrm{F}=25 ; \text { two-tail ' } \mathrm{t} \text { ' test, } \mathrm{p}<0.05 \\
\begin{array}{l}\text { Dimensions and its elements with statistically significant } \\
\text { difference }\end{array}\end{array}$ & \multicolumn{2}{|l|}{ Means of Responses } \\
\cline { 2 - 3 } $\begin{array}{l}\text { D1: Mathematics Importance and Usefulness (9 elements) } \\
\text { - Mathematics is of great importance to a country's } \\
\quad \text { development }\end{array}$ & $4.44(\mathrm{M})$ & Post \\
\hline
\end{tabular}




\begin{tabular}{|l|l|l|}
\hline $\begin{array}{l}\text { D2: Mathematics Enjoyment and Aptitude (15 elements) } \\
\text { - Sometimes I would like to do more mathematics } \\
\text { problems than are given in class }\end{array}$ & $3.28(\mathrm{~F})$ & $3.84(\mathrm{~F})$ \\
$\quad \begin{array}{l}\text { I feel uneasy when someone talks to me about } \\
\text { mathematics }\end{array}$ & $2.48(\mathrm{~F})$ & $1.56(\mathrm{~F})$ \\
\hline $\begin{array}{l}\text { D3: Science Enjoyment and Aptitude (15 elements) } \\
\text { - Science is something which I enjoy very much }\end{array}$ & $3.2(\mathrm{~F})$ & $3.68(\mathrm{~F})$ \\
\hline $\begin{array}{l}\text { D4: Science Importance and Usefulness (9 elements) } \\
\text { - Science is something which I enjoy very much } \\
\text { - There is little need for science in most jobs }\end{array}$ & $4.16(\mathrm{M}) ; 3.80(\mathrm{~F})$ & $4.04(\mathrm{~F})$ \\
\hline $\begin{array}{l}\text { D5: Math and Science Instruction (17 elements) } \\
\text { - I have a real desire to learn mathematics } \\
\text { - Use of flight sim in learning math and science }\end{array}$ & $\begin{array}{l}3.36(\mathrm{M}) ; 2.76(\mathrm{~F}) \\
4.27(\mathrm{M}) ; 3.81(\mathrm{~F})\end{array}$ & $\begin{array}{l}4.28(\mathrm{~F}) \\
4.41(\mathrm{~F})\end{array}$ \\
\hline
\end{tabular}

Table 1: Attitude survey responses

Analysis of the math and science content knowledge pre-post assessment of the participants indicated a positive improvement that was statistically significant $(\mathrm{p}<0.05)$. Data for the 2018 cohort is shown in Fig. 3. The pretest average of the participants on the math content assessment was $31.8 \%$ while on the post-test the average was $59.4 \%$. The average score of the science pretest was $33 \%$ while on the post-test the participants averaged $43.7 \%$.
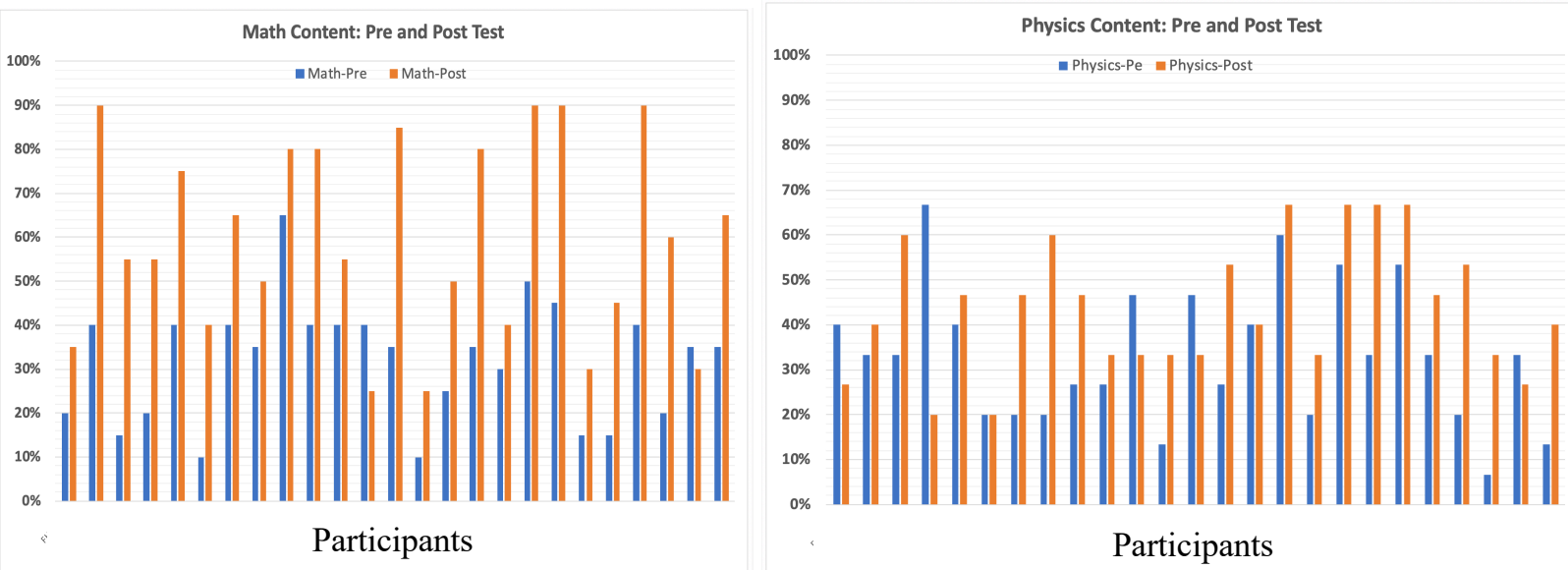

Figure 3: Performance on math and science content assessment

The participating students were also surveyed to determine their perceptions of the camp. Some typical responses are quoted below:

"The best thing I learned at camp was learning new ways to do math, and science.

We learned how to do math problems without using anything to help me.

The best thing I like is flying the flight simulator and using excel to calculate our data.

I like about the camp is how the teacher teach science tech engineering and math 
I liked using the flight simulator and interacting with others."

\section{Conclusions and Future Work}

The results indicated that the learning environment with the active learning modules was effective in increasing the self-efficacy of the participating students, improving their attitudes towards STEM, and enhancing their content knowledge. The project team members have installed the software and a large screen set up in one local middle school (Fig. 4) and they will be installing similar one in another middle school in 2019. In addition, approximately 40 middle school math and science teachers have been imparted professional development and trained to implement the pedagogical approach in their classrooms. A third and final summer camp for students will be held in the summer of 2019. The project team is in the process of developing additional lesson modules which will be piloted during the 2019 summer camp.

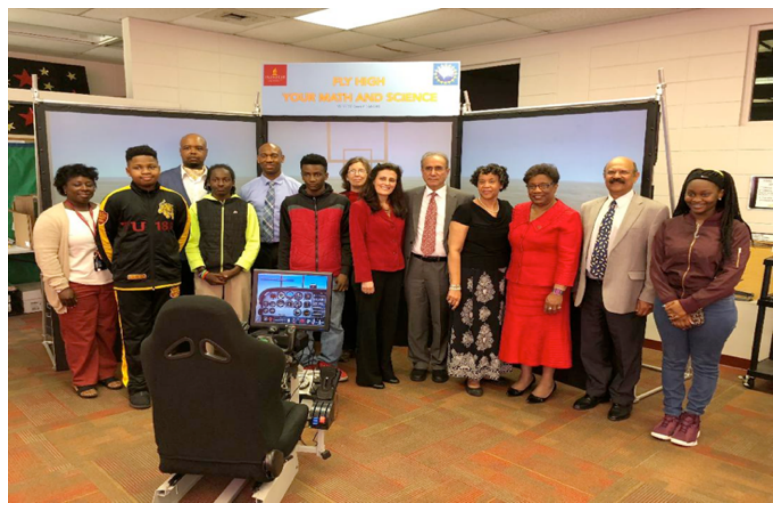

Figure 4: Simulator setup in a local middle school

\section{Acknowledgment}

This work is supported by the Innovative Technology Experiences for Students and Teachers (ITEST) program of the National Foundation (NSF), Grant\# 1614249.

\section{References}

[1] Pew Research (2015), http://www.pewresearch.org/fact-tank/2017/02/15/u-s-studentsinternationally-math-science/, accessed on Jan. 29, 2019

[2] NCES (2017), https://nces.ed.gov/pubs2017/2017144.pdf, accessed on Jan. 29, 2019

[3] NEA (2019). Accessed on Jan. 29, 2019, https://www.nea.org/assets/docs/18021-

Closing_Achve_Gap_backgrndr_7-FINAL.pdf

[4] C. T. Clotfelter, H. F. Ladd and J. Vigdor, "Who teaches whom? Race and the distribution of novice teachers," Economics of Education Review vol. 24, 2005, pp. 377-392, accessed on Jan. 29, 2019, http://people.terry.uga.edu/mustard/courses/e8420/Clotfelter-Teachers.pdf

[5] K. Haycook and C. Crawford, "Closing the Teacher Quality Gap," Educational Leadership, Poverty and Learning, vol. 67 (7), April 2008, pp. 14-19, accessed on Jan. 29, 2019. http://www.ascd.org/publications/educational-leadership/apr08/vol65/num07/Closing-the-

Teacher-Quality-Gap.aspx

[6] D. Goldhaber, V. Quince, R. Theobald "Has It Always Been This Way? Tracing the Evolution of Teacher Quality Gaps in U.S. Public Schools," American Education Research Journal, vol. 55 Issue 1, Feb.2018, pp. 171-201

[7] N. Huntington-Klein and F. E. Ackert, "The Long Road to Equality: A Meta-Regression Analysis of Changes in the Black Test Score Gap over Time," Social Sciences Quarterly, Sep. 2018, vol. 99(3):1119-1133. doi: 10.1111/ssqu.12483

[8] HSSE (2010). Charting the Path from Engagement to Achievement: A Report on the 2009 High School Survey of Student Engagement Ethan Yazzie-Mintz, Director, High School Survey 
of Student Engagement, accessed on Jan 29, 2019, https://www.wisconsinpbisnetwork.org/assets/files/2013\%20Conference/Session\%20Material/Hi ghSchoolSurveyStudentEngagement.pdf

[9] J. M. Bridgeland, J. J. DiIulio and K. B. Morison, "The Silent Epidemic: Perspectives of High School Dropouts," March 2006, A report by Civic Enterprises in association with Peter D. Hart Research Associates for the Bill \& Melinda Gates Foundation, accessed on Jan. 29, 2019, https://files.eric.ed.gov/fulltext/ED513444.pdf

[10] M. M. Handelsman, W. L. Briggs, N. Sullivan, N., and A. Towler, "A measure of College Student Course Engagement," The Journal of Educational Research, Vol. 98 (3), January/February, 2005

[11] J. A. Fredricks, P. C. Blumenfeld and A. H. Paris, "School engagement: Potential of the concept, state of the evidence," Review of Educational Research, vol. 74, pp. 59-109

[12] J. W. Thomas (2000). A review of research on project-based learning, accessed on Jan. 29. 2019, www.bie.org/index.php/site/RE/pbl_research/29

[13] B. D. Jones, "Motivating students to engage in learning: The MUSIC model of academic motivation," International Journal of Teaching and Learning in Higher Education, vol. 21 (2), 272-285, accessed on Jan. 29, 2019, http://files.eric.ed.gov/fulltext/EJ899315.pdf

[14] R. J. Marzano, D. J. Pickering and T. Heflebowen, The highly engaged classroom, Marzano Research Laboratory, 2011

[15] A. Bandura, "Self-efficacy mechanism in human agency," American Psychologist, vol. 37 (2), pp. 122-147, 1982, doi:10.1037/0003-066X.37.2.122

[16] A. Carroll and S. Houghton, "Self-efficacy and academic achievement in Australian high school students: The mediating effects of academic aspirations and delinquency," Journal of Adolescence, vol. 32(4), December 2008, pp. 797-817

[17] J. D. Johnson, S. S. Starobin, F. S. Laanan, D. Russell, "The influence of selfEfficacy on student academic success, student degree aspirations, and transfer planning," The

OCCRP Research Brief, 7. Series on STEM Student Success Literacy Project. 2012, Ames, IA: Office of Community College Research and Policy.

[18] C.W. Loo and J.L.F. Choy, "Sources of Self-Efficacy Influencing Academic Performance of Engineering Students," American Journal of Educational Research 1(3), pp. 86-92, April

2013DOI: 10.12691/education-1-3-4

[19] S. E. Motlagh, K. Amrai, M. J. Yazdani, H. A. Abderahim and H. Sourie, "The relationship between self-efficacy and academic achievement in high school students," Procedia - Social and Behavioral Sciences, vol. 15, 2011, Pages 765-768, accessed on Jan. 29, 2019, https://doi.org/10.1016/j.sbspro.2011.03.180

[20] R. Shkullako, "The relationship between self-efficacy and academic performance in the context of gender among Albanian students," European Academic Research, Vol. 1(4), July 2013, accessed on Jan. 29, 2019, http://www.euacademic.org/UploadArticle/33.pdf

[21] E. Hanlon and Y. Schneider, "Improving math proficiency through self efficacy training," American Educational Research Association, Annual Meeting, Montreal, Quebec, Canada, April $19-23,1999$

[22] X. Liu and H. Koirala, "The Effect of Mathematics Self-Efficacy on Mathematics Achievement of High School Students," NERA Conference Proceedings 2009, Paper 30 [23] R. A. Louis and J. M. Mistele, "The differences in scores and self-efficacy by student gender in mathematics and science," International Journal of Science and Mathematics Education, vol. 10 (5), pp. 1163-1190, Oct. 2012, 
[24] Wideview, accessed on Jan. 29, 2019, https://www.wideview.it/

[25] FSUIPC, accessed on Jan. 29, 2019, http://www.schiratti.com/dowson.html

[26] R. W. Bybee (2009). The BSCS 5E instructional model and 21st century Skills", A

commissioned paper prepared for a workshop on exploring the intersection of science education and the development of 21st century skills, accessed on Jan. 29, 2019

https://sites.nationalacademies.org/cs/groups/dbassesite/documents/webpage/dbasse 073327.pdf 